\title{
Marine microalgae monosaccharide fluctuations as a stress response to nutrients inputs
}

\author{
Tomásia Fernandes $^{\mathrm{a}}$, Igor Fernandes ${ }^{\mathrm{a}}$, Carlos A.P. Andrade ${ }^{\mathrm{b}, \mathrm{c}}$, Artur Ferreira ${ }^{\mathrm{d}}$, Nereida Cordeiro ${ }^{\mathrm{a}, *}$ \\ a University of Madeira, Faculty of Sciences and Engineering, 9000-390 Funchal, Madeira, Portugal \\ b Mariculture Center of Calheta, Vila da Calheta, 9370-133 Calheta, Madeira, Portugal \\ c CIIMAR, Interdiciplinary Centre of Marine and Environmental Research, Rua dos Bragas 289, 4050-123 Porto, Portugal \\ d CICECO - Aveiro Institute of Materials, Escola Superior de Tecnologia e Gestão de Águeda, University of Aveiro, 3810-193 Aveiro, Portugal
}

\section{A R T I C L E I N F O}

\section{Keywords:}

Monosaccharides

Nutrient availability

Nannochloropsis gaditana

Rhodomonas marina

Isochrysis sp.

\begin{abstract}
A B S T R A C T
The monosaccharide patterns of the microalgae species Nannochloropsis gaditana, Rhodomonas marina and Isochrysis sp. were assessed, to verify if nutrients availability had an impact on these parameters. Isochrysis sp. and Rhodomonas marina monosaccharides content decreased $13-94 \%$ as the nutrients availability increased. The relative abundance of monosaccharides depicted that, at low nutrients availabilities, Rhodomonas marina and Isochrysis sp. had preference for glucans synthesis, accounting for up to $75 \%$ of the monosaccharides detected. Linking the monosaccharides trends with the phylogeny and glycolipid data, it was possible to establish which monosaccharides had a structural and/or storage role in the microalgae studied. Thermal analysis revealed that the microalgae submitted to low nutrient input treatments presented a reduced assimilation of the inorganic compounds. Nutrient concentrations affected microalgae monosaccharide patterns, highlighting their taxonomic differences.
\end{abstract}

\section{Introduction}

Microalgae are photosynthetic organisms known as potential sources of natural compounds which can be applied in therapeutics and biotechnological applications [33]. The ability of these microorganisms to readily adapt to growth fluctuating conditions, attributed to their metabolic flexibility, constitutes an advantage in modulating their biomass composition for commercial purposes [25,28]. In this regard, strategies like the manipulation of parameters such as media nutrient concentrations can be used in order to modify the nature, amount and composition of the products synthesized [24].

Carbohydrates are the main products of photosynthetically-fixed carbon which can be stored intracellularly in multiple forms, such as starch, or deposited into structural polysaccharides [8,10,37]. Monosaccharides are the building-blocks of the latest molecules and their composition can give an insight of polysaccharide predominance in microalgae $[6,23,38]$. This is a crucial factor when selecting species as feed sources in aquaculture and for biotechnological applications, since polysaccharides composition determines the microalgae breakage and digestibility, thus conditioning the extraction of cell wall coated valued products $[2,6]$.

The polysaccharides synthesized by microalgae species can be applied in several areas [25]. For instance, starch and cellulose can be anaerobically converted into bioethanol, whereas $\beta$-D-glucans (e.g. laminarans) are under increasing attention due to their potential in therapeutic applications $[8,25]$. $\beta$-D-glucans are known for enhancing the host immune system by binding to $\beta$-glucan receptors of cells involved in immune responses, such as macrophages and neutrophils $[14,33]$. Sulphated polysaccharides have multiple biological activities, namely antiviral, antioxidant and anti-inflammatory [32]. In addition, polysaccharides can be used in food technology as emulsifiers and stabilizers in various food products [25].

To enhance microalgae compounds productivity it is essential to understand the metabolic pathways that lead to the partitioning of carbon precursors into the multiple forms of carbon storage $[8,20,22]$. Organizational differences within microalgae species might affect processes such as photosynthesis and carbon flux through metabolic networks [20]. The present study aimed to evaluate the impact of nutrient availability on the carbohydrate profile of three marine microalgae commonly used in aquaculture (Nannochloropsis gaditana, Rhodomonas marina and Isochrysis sp.) and attempt to link the monosaccharides composition with the origin based carbohydrate on phylogenetic data.

\footnotetext{
* Corresponding author.

E-mail address: ncordeiro@uma.pt (N. Cordeiro).
} 
Table 1

Components of the growth medium culture and respective concentrations used in the final growth media $\left(\mathrm{mg} \mathrm{L}^{-1}\right)$.

\begin{tabular}{|c|c|c|c|c|c|}
\hline \multirow[t]{2}{*}{ Component } & \multicolumn{5}{|c|}{ Concentration in final growth medium $\left(\mathrm{mg} \mathrm{L}^{-1}\right)$} \\
\hline & $\mathrm{T} 1$ & $\mathrm{~T} 2$ & Т3 & $\mathrm{T} 4$ & T5 \\
\hline $\mathrm{NaNO}_{3}$ & 43 & 85 & 170 & 340 & 680 \\
\hline $\mathrm{KH}_{2} \mathrm{PO}_{4}$ & 3 & 7 & 14 & 27 & 54 \\
\hline EDTA & 2 & 4 & 8 & 15 & 31 \\
\hline $\mathrm{FeCl}_{3} \cdot 6 \mathrm{H}_{2} \mathrm{O}$ & 1 & 3 & 5 & 11 & 22 \\
\hline $\mathrm{ZnCl}_{2}$ & 0.03 & 0.07 & 0.14 & 0.27 & 0.54 \\
\hline $\mathrm{ZnSO}_{4}$ & 0.07 & 0.14 & 0.29 & 0.57 & 1.15 \\
\hline $\mathrm{MnCl}_{2} \cdot 2 \mathrm{H}_{2} \mathrm{O}$ & 0.04 & 0.08 & 0.16 & 0.32 & 0.65 \\
\hline $\mathrm{Na}_{2} \mathrm{MoO}_{4} \cdot 2 \mathrm{H}_{2} \mathrm{O}$ & 0.01 & 0.01 & 0.02 & 0.05 & 0.10 \\
\hline $\mathrm{CoCl}_{2} \cdot 6 \mathrm{H} 2 \mathrm{O}$ & 0.01 & 0.01 & 0.02 & 0.05 & 0.10 \\
\hline $\mathrm{CuSO}_{4} \cdot 5 \mathrm{H}_{2} \mathrm{O}$ & 0.01 & 0.01 & 0.03 & 0.05 & 0.10 \\
\hline $\mathrm{MgSO}_{4} \cdot 7 \mathrm{H}_{2} \mathrm{O}$ & 0.12 & 0.25 & 0.49 & 0.98 & 1.97 \\
\hline \multicolumn{6}{|l|}{ Vitamins } \\
\hline Tiamine & 0.01 & 0.02 & 0.04 & 0.07 & 0.14 \\
\hline Biotin & 0.001 & 0.003 & 0.005 & 0.010 & 0.020 \\
\hline $\mathrm{B}_{12}$ & 0.001 & 0.002 & 0.003 & 0.006 & 0.012 \\
\hline
\end{tabular}

\section{Materials and methods}

\subsection{Algal growth}

The Eustigmatophyte Nannochloropsis gaditana, Cryptophyte Rhodomonas marina and Prymnesiophyte Isochrysis sp., were supplied by the Mariculture Center of Calheta (Madeira, Portugal). Each nonaxenic microalgal strain was cultured in $500 \mathrm{~mL}$ of enriched seawater with commercial culture medium Nutribloom Plus (Necton, Portugal).

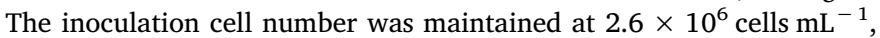
for Isochrysis sp. and N. gaditana, and $1.4 \times 10^{5}$ cells $\mathrm{mL}^{-1}$, for $R$. marina. Five different volumes: 250 (T1), 500 (T2), 1000 (T3), 2000 (T4) and 4000 (T5) $\mu \mathrm{L}$ of nutrient solution $\mathrm{L}^{-1}$ of seawater (previously adjusted to a salinity of $25 \mathrm{~g} \mathrm{~L}^{-1}$ ), were used for the preparation of the growth media. The nutrient concentrations in the final growth medium are presented in Table 1.

Aerated cultures (with compressed air - $125 \mathrm{~mL} \mathrm{min.}{ }^{-1}$ ) were maintained at $23{ }^{\circ} \mathrm{C}$, with a photoperiod of $18: 6 \mathrm{~h}$ light/dark cycles, at a light intensity of $52 \mu \mathrm{mol} \mathrm{m}{ }^{-2} \mathrm{~s}^{-1}$ provided by daylight fluorescent lamps as in Le Chevanton et al. [9]. The microalgae were harvested at stationary phase. More detailed information on the experimental design and algal growth is referred in Fernandes et al. [16].

\subsection{Carbohydrate composition}

\subsubsection{Acid hydrolysis and alditol acetate derivatization}

Monosaccharides were analysed as alditol acetate according to modified Blakeney et al. [5]. Briefly, $10 \mathrm{mg}$ of dried algal biomass were exposed to a two stage sulphuric acid hydrolysis $\left(3 \mathrm{~h}\right.$ at $20{ }^{\circ} \mathrm{C}$ in $72 \%$ sulfuric acid, followed by $2.5 \mathrm{~h}$ at $100^{\circ} \mathrm{C}$, after water addition, in an oil bath). After cooling to room temperature, $200 \mu \mathrm{L}$ of internal standard (2-deoxyglucose $-20 \mathrm{mg} \mathrm{mL}^{-1}$ ) was added to the hydrolysate. To $1 \mathrm{~mL}$ aliquot of hydrolysate mixture, $200 \mu \mathrm{L}$ of $25 \%$ ammoniac were added and the reduction of monosaccharides to alditol was performed. The reduction procedure involved the addition of $100 \mu \mathrm{L}$ of $3 \mathrm{M}$ ammoniac solution containing $150 \mathrm{mg} \mathrm{mL}^{-1}$ of sodium borohydride and the incubation at $30^{\circ} \mathrm{C}$ for $1 \mathrm{~h}$ in a water bath. Then two additions of $50 \mu \mathrm{L}$ of glacial acetic acid, followed by homogenization, were carried out. Alditol acetylation was performed by the addition of $0.45 \mathrm{~mL}$ of 1-methylimidazole and $3 \mathrm{~mL}$ of acetic anhydride to $0.3 \mathrm{~mL}$ of the previous mixture. Next, the solution was incubated at $30{ }^{\circ} \mathrm{C}$ for $30 \mathrm{~min}$. in a water bath. The derivatized monosaccharides (alditol acetate) were extracted with dichloromethane being posteriorly washed several times with water. The solvent was evaporated under a nitrogen atmosphere. The standard solutions were also derivatized prior to GC-MS analysis. At least two replicates were made.

\subsubsection{GC-MS analysis}

Monosaccharides alditol acetates were analysed by gas chromatography (Agilent HP 6890) equipped with a mass selective detector (Agilent 5973) and a capillary column DB-225 J \& W (30 m $\times 0.25 \mathrm{~mm}$ inner diameter, $0.15 \mu \mathrm{m}$ film thickness) from Agilent. The inlet temperature was $220^{\circ} \mathrm{C}$ and the column temperature was held at $220{ }^{\circ} \mathrm{C}$ for $5 \mathrm{~min}$., ramped at $10^{\circ} \mathrm{min} .^{-1}$ to $230^{\circ} \mathrm{C}$ and kept at this temperature for $6 \mathrm{~min}$. The transfer line temperature was $280{ }^{\circ} \mathrm{C}$, the split ratio was 1:30 and Helium was used as the carrier gas with a flow rate of $1.2 \mathrm{~mL} \mathrm{~min}^{-1}$. The derivatized monosaccharides were identified by comparing the retention times and mass spectra fragmentation with that obtained through injection of the standards. The monosaccharides quantification was made through the calculated response factor of each standard towards the internal standard. The standards used were 2-deoxyglucose, $\mathrm{L}(+$ )arabinose, $\mathrm{D}(+)$ xylose, $\mathrm{D}(+$ )galactose, $\mathrm{D}(+)$ glucose, $\mathrm{D}(+)$ mannose, $\mathrm{D}(+)$ rhamnose, $\mathrm{D}(+)$ fucose purchased at Sigma-Aldrich (St. Louis, MO, USA). Four replicates were performed for each GC-MS analysis being the results presented as the mean value \pm standard deviation (SD) of monosaccharides expressed in $\mathrm{mg} \mathrm{g}^{-1}$ of dry biomass weight (DW). All the reagents used had analytical grade.

\subsection{Thermal analysis}

Thermogravimetric analysis (TGA) was performed using a SETSYS Evolution 1750 thermogravimetric analyzer (Setaram) from room temperature up to $700{ }^{\circ} \mathrm{C}$, at a heating rate of $20^{\circ} \mathrm{C} \mathrm{min} .^{-1}$ and under oxygen flux (200 mL min. $\left.{ }^{-1}\right)$.

\subsection{Statistical analysis}

Statistical analysis of the data was carried out using the software IBM SPSS Statistics 23. Differences between treatments were assessed by one-way analysis of variance (ANOVA) followed by a Tukey's PostHoc analysis; p-values $<0.05$ were considered to be statistically significant. Principal component analysis (PCA) was applied to summarise the information in a reduced number of principal components. Varimax rotation was selected to represent the planar projection of the loadings (variables) for the two principal components.

\section{Results and discussion}

\subsection{Monosaccharides profile}

Monosaccharide compositional analysis can give an indication of the original polysaccharide structure, cell wall composition and storage products based on phylogeny information from the literature $[8,39]$. In this regard, the assessment of the nutrient concentration effect on microalgae is essential to give an insight of the structural and functional variations that lead to a successful adaptation of each species. Table 2 shows the variation in the monosaccharides detected among the three marine microalgae studied. The results indicate significant differences ( $\mathrm{p}<0.05)$ in the amount and composition of monosaccharides in the three microalgae grown under different nutrient availabilities.

Mannose, galactose and glucose were identified in N. gaditana and Isochrysis sp. in all treatments applied. However, the proportions of these monosaccharides have changed between and within these two marine microalgae species. The three monosaccharides are epimers mannose at C2 position of glucose and galactose at C4 position [11]. Like glucose, mannose is a key precursor of the nucleotide-sugar interconversion pathway and can be derived from fructose 6-phosphate whereas galactose is known as a key structural component of chloroplast membranes [3,19,35].

$N$. gaditana displayed the more complex mixture of monosacchar- 
Table 2

Monosaccharide profile of Nannochloropsis gaditana, Rhodomonas marina and Isochrysis sp. according to nutrient availabilities.

\begin{tabular}{|c|c|c|c|c|c|c|}
\hline & \multirow[t]{2}{*}{ Monosaccharide (mg g $\left.{ }^{-1} \mathrm{DW}\right)$} & \multicolumn{5}{|l|}{ Treatment } \\
\hline & & $\mathrm{T} 1$ & $\mathrm{~T} 2$ & T3 & $\mathrm{T} 4$ & T5 \\
\hline \multirow[t]{7}{*}{ N. gaditana } & Fucose & $0.58 \pm 0.05^{\mathrm{a}}$ & $0.23 \pm 0.03^{\mathrm{b}}$ & $0.61 \pm 0.04^{\mathrm{a}}$ & $0.71 \pm 0.06^{\mathrm{a}}$ & $1.31 \pm 0.15^{\mathrm{c}}$ \\
\hline & Xylose & $1.20 \pm 0.09^{\mathrm{a}}$ & $0.76 \pm 0.02^{\mathrm{a}}$ & $2.37 \pm 0.34^{\mathrm{b}}$ & $5.43 \pm 0.25^{c}$ & $6.05 \pm 0.31^{\mathrm{d}}$ \\
\hline & Rhamnose & $0.55 \pm 0.06^{\mathrm{a}}$ & $0.46 \pm 0.03^{\mathrm{a}}$ & $3.42 \pm 0.30^{\mathrm{b}}$ & $7.77 \pm 0.40^{c}$ & $8.62 \pm 0.36^{\mathrm{d}}$ \\
\hline & Mannose & $0.26 \pm 0.03^{\mathrm{a}}$ & $0.55 \pm 0.04^{\mathrm{b}}$ & $0.30 \pm 0.01^{\mathrm{a}}$ & $1.76 \pm 0.16^{\mathrm{c}}$ & $2.64 \pm 0.09^{\mathrm{d}}$ \\
\hline & Galactose & $2.25 \pm 0.07^{\mathrm{a}}$ & $2.09 \pm 0.12^{\mathrm{a}}$ & $4.33 \pm 0.39^{\mathrm{b}}$ & $10.15 \pm 0.50^{c}$ & $11.02 \pm 0.62^{c}$ \\
\hline & Glucose & $13.52 \pm 0.43^{\mathrm{a}}$ & $12.37 \pm 1.04^{\mathrm{a}}$ & $24.01 \pm 0.66^{\mathrm{b}}$ & $46.81 \pm 0.67^{c}$ & $50.15 \pm 1.18^{\mathrm{d}}$ \\
\hline & Total & $18.57 \pm 0.63^{\mathrm{a}}$ & $16.46 \pm 1.18^{\mathrm{a}}$ & $35.04 \pm 1.36^{\mathrm{b}}$ & $72.64 \pm 1.41^{\mathrm{c}}$ & $79.79 \pm 1.61^{\mathrm{d}}$ \\
\hline \multirow[t]{6}{*}{ R. marina } & Fucose & n.d. & n.d. & n.d. & $0.06 \pm 0.00$ & n.d. \\
\hline & Rhamnose & $0.64 \pm 0.05^{\mathrm{a}}$ & n.d. & n.d. & n.d. & $2.20 \pm 0.09^{\mathrm{b}}$ \\
\hline & Mannose & n.d. & n.d. & n.d. & n.d. & $0.91 \pm 0.05$ \\
\hline & Galactose & $2.23 \pm 0.28^{\mathrm{a}}$ & $12.21 \pm 0.99^{\mathrm{b}}$ & $8.93 \pm 1.17^{c}$ & $1.74 \pm 0.10^{\mathrm{a}}$ & n.d. \\
\hline & Glucose & $142.66 \pm 2.04^{\mathrm{a}}$ & $195.29 \pm 3.61^{\mathrm{b}}$ & $27.78 \pm 1.08^{\mathrm{c}}$ & $0.25 \pm 0.02^{\mathrm{d}}$ & n.d. \\
\hline & Total & $145.53 \pm 2.33^{\mathrm{a}}$ & $207.50 \pm 4.59^{\mathrm{b}}$ & $36.71 \pm 2.11^{c}$ & $2.06 \pm 0.10^{\mathrm{d}}$ & $3.11 \pm 0.12^{\mathrm{d}}$ \\
\hline \multirow[t]{6}{*}{ Isochrysis sp. } & Arabinose & $3.62 \pm 0.17^{\mathrm{a}}$ & $3.80 \pm 0.60^{\mathrm{a}}$ & $4.59 \pm 0.28^{b}$ & $4.31 \pm 0.15^{\mathrm{ab}}$ & $4.59 \pm 0.15^{\mathrm{b}}$ \\
\hline & Xylose & $0.29 \pm 0.03^{\mathrm{a}}$ & $0.25 \pm 0.02^{\mathrm{a}}$ & $0.57 \pm 0.06^{\mathrm{b}}$ & $0.51 \pm 0.04^{\mathrm{bc}}$ & $0.44 \pm 0.06^{c}$ \\
\hline & Mannose & $8.97 \pm 0.91^{\mathrm{a}}$ & $8.99 \pm 0.95^{\mathrm{a}}$ & $11.96 \pm 0.92^{\mathrm{b}}$ & $17.32 \pm 0.87^{c}$ & $17.94 \pm 1.03^{c}$ \\
\hline & Galactose & $23.48 \pm 0.96^{\mathrm{a}}$ & $23.79 \pm 1.97^{\mathrm{a}}$ & $31.44 \pm 1.10^{\mathrm{b}}$ & $30.74 \pm 1.12^{\mathrm{b}}$ & $33.46 \pm 2.49^{\mathrm{b}}$ \\
\hline & Glucose & $136.77 \pm 2.80^{\mathrm{a}}$ & $107.78 \pm 3.54^{\mathrm{b}}$ & $76.91 \pm 1.87^{c}$ & $35.37 \pm 1.78^{\mathrm{d}}$ & $35.41 \pm 1.43^{\mathrm{d}}$ \\
\hline & Total & $173.13 \pm 3.81^{\mathrm{a}}$ & $144.61 \pm 5.64^{\mathrm{b}}$ & $125.48 \pm 4.03^{c}$ & $88.24 \pm 1.54^{\mathrm{d}}$ & $91.84 \pm 4.82^{\mathrm{d}}$ \\
\hline
\end{tabular}

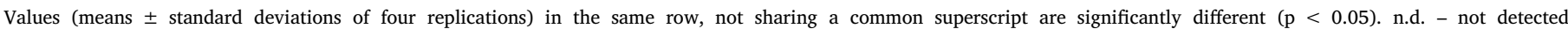
$\left(<0.01 \mathrm{mg} \mathrm{g}^{-1}\right)$

ides being identified by six monosaccharides: fucose, xylose, rhamnose, mannose, galactose and glucose. Fig. 1a exhibits the variation of monosaccharide proportions in $N$. gaditana. The predominant sugar in $N$. gaditana was glucose accounting for $63-75 \%$ of total monosaccharides (TM), regardless the treatments applied. This observation is in accordance with previous results obtained by Brown [6] for another strain of Nannochloropsis ( $N$. oculata) cultured in $\mathrm{f} / 2$ medium, where glucose accounted for $68 \%$ of TM. Furthermore, a fivefold increase was observed in TM content in response to nutrient input (Table 2). This trend might suggest that $N$. gaditana responded to the nutrients inputs by accumulating low molecular weight carbohydrates which may act as osmoregulators or as energy reserves [27]. Through comparison with the specific growth rate present in Fernandes et al. [16], is possible to note that treatments that induced low specific growth rates $\left(0.47-0.52 \mathrm{~d}^{-1}\right)$ lead to higher monosaccharide accumulation.

A former study reported that around $75 \%$ of the inner cell wall layer composition of $N$. gaditana is cellulose $((1 \rightarrow 4)-\beta$-glucan $)$ [34]. However, the matrix and fibrillar fractions of cell wall possess other saccharides than glucans, which may interconnect cellulose micro fibrils $[18,34]$. Through Fig. 1a, a slight decrease of glucose proportion in contrast to rhamnose is observed. Since terminal rhamnose residues have been found to occur in the cell wall of these microalgae, this might suggest that under high nutrient concentrations $N$. gaditana displaced preference towards rhamnans production for structural purposes and/ or for suppress the effects of salt stress [34].

Fig. 1b displays the monosaccharides variation in $R$. marina with nutrients concentration. Through this figure it is possible to observe that the treatments induced an alteration of the predominant sugars in this microalga. Thus, for $\mathrm{T} 1$ to $\mathrm{T} 3$ the predominant sugar was glucose (76-98\% of $\mathrm{TM})$ changing for galactose at $\mathrm{T} 4$ (85\% of $\mathrm{TM})$ and rhamnose at $\mathrm{T} 5(71 \%$ of $\mathrm{TM})$. The predominance of glucose in $\mathrm{T} 1$ to T3 suggests that these treatments induced an increase in starch $((1 \rightarrow$ 4)- $\alpha$-glucan), a storage polysaccharide that it is known to accumulate in $R$. marina under unfavorable conditions [30]. Since the inorganic carbon (Ci) was kept constant, upon treatments, this may have imposed a stoichiometric imbalance between nutrients and the Ci explaining the results obtained.

According to Silva et al. [36] a low rate of photosynthetic activity induced an increase in the carbohydrate content for Rhodomonas sp. In $R$. marina, treatments with lowest nutrient availabilities (T1 and T2) had the highest contents of monosaccharides. Since treatments with low nutrients concentrations, encompass low concentrations of elements, such as magnesium and iron, needed for the maintenance of photosynthetic reactions, this observation might support the assumption that under stressful conditions affecting microalgae photosynthesis efficiency, the metabolic processes are channelled up towards carbohydrate accumulation, in order to fulfil cells requirements [24]. Moreover, Cruz et al. [40] evidenced that low nutrient content led to a higher carbon fixation rate in Rhodomonas sp. Perhaps for having the best $\mathrm{Ci}$ and nutrients ratio for carbohydrate accumulation, the highest monosaccharide content ( $21 \%$ of dry biomass) was observed for the second treatment with the lowest nutrients concentration.

In Isochrysis sp. the main sugars were galactose and glucose representing 75-93\% of TM despite of their proportions have changed between treatments (Fig. 1c). In a former study presented by Brown [6], glucose was pointed as the main monosaccharide for two strains of Isochrysis genus in $\mathrm{f} / 2$ medium accounting 70 and $77 \%$ of TM. Moreover, mannose had a fourfold increase (Fig. 1c) presenting a similar trend to galactose which increased by a two and a half fold from T1 to T5. In contrast, glucose decreased by as much as $50 \%$ with nutrients input. As previously mentioned, fructose 6-phosphate is the major precursor of the activated forms of both glucose and mannose and therefore some competition might occur between the productions of these two monosaccharides explaining why they have divergent trends. Having in account that the increasing trend of both mannose and galactose is similar to that of glycolipids and cell densities, former studied by Fernandes et al. [16], this might indicate that the biosynthesis of these, might serve structural purposes. For instance, monogalactosyl-diacylglycerol and digalactosyl-diacylglycerol, main components of chloroplast membranes, require galactose for their synthesis $[12,39]$. In this microalga the TM content in treatments with low nutrient availabilities displayed an analogous trend to $R$. marina.

Many carbohydrates meet their catabolic fate in glycolysis after being hydrolyzed to free sugars and transformed into one of the glycolytic intermediates [19,31]. Thus the predominance of glucose in Isochrysis sp. with high $\mathrm{Ci}$ and low nutrients concentration in growth media, might derive from the predominance of storage polysaccharides, namely soluble linked $(1 \rightarrow 3$ )- $\beta$-glucan (chrysolaminarin) [30]. Thus, these microalgae might respond to nutrients input by enhancing the rate of glycolysis from glucose derived from $\mathrm{Ci}$ fixation and/or storage polysaccharides to yield the intermediates for lipid biosynthesis, namely acetyl Co-A, a fatty acid precursor that can be supplied by the 
(a) $\square$ Glucose $\approx$ Galactose $\bowtie$ Rhamnose $\bowtie$ Xylose $\square$ Mannose $\approx$ Fucose

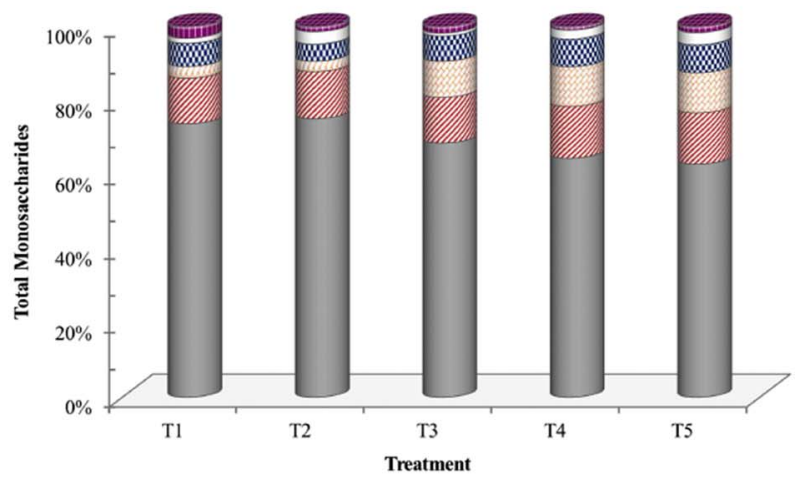

(b)

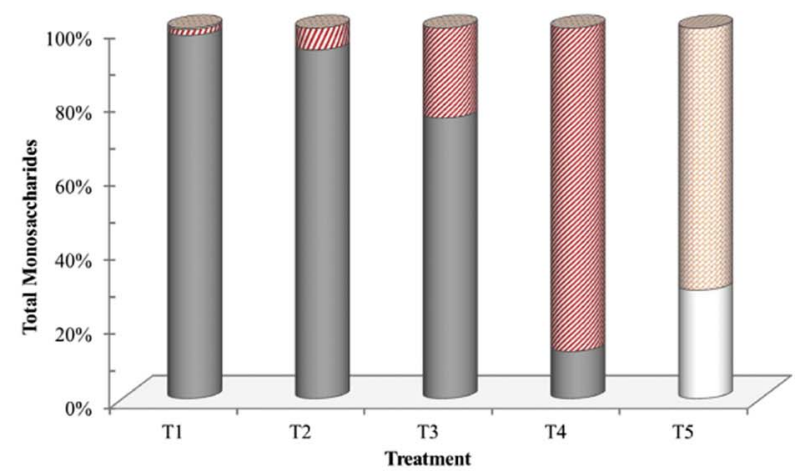

(c) $\square$ Glucose $\approx$ Galactose $\square$ Mannose $\quad$ Arabinose $\approx$ Xylose

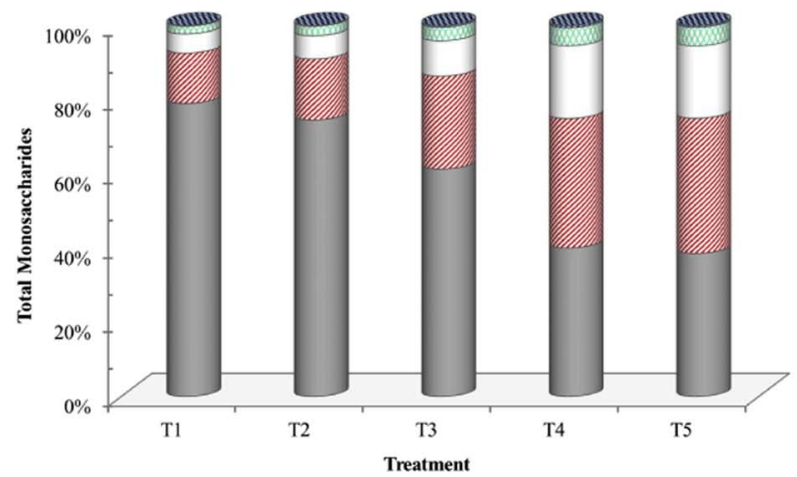

Fig. 1. Monosaccharide proportions regarding growth media nutrient availability in (a) Nannochloropsis gaditana, (b) Rhodomonas marina and (c) Isochrysis sp.

glycolytic pathway and the Benson-Calvin cycle [29]. Furthermore, former studies have pointed that under $\mathrm{N}-, \mathrm{S}-, \mathrm{K}-, \mathrm{Mg}$ - starved conditions and high $\mathrm{CO}_{2}$ concentrations microalgae tend to increase their starch accumulation supporting the observations reported in this study $[13,21,29]$.

$N$. gaditana responded in a different way to the nutrient input, increasing the monosaccharide content as the nutrients input increased. Since microalgae have diverse cellular organizational schemes for carbon fixation and carbohydrate storage, the composition and metabolism of carbohydrates differ significantly from species to species $[8,20]$.

\section{2. $T G A$}

The thermogravimetric analysis (TGA) and the derivative TGA (DTGA) are useful tools for assessing microalgae biomass and its

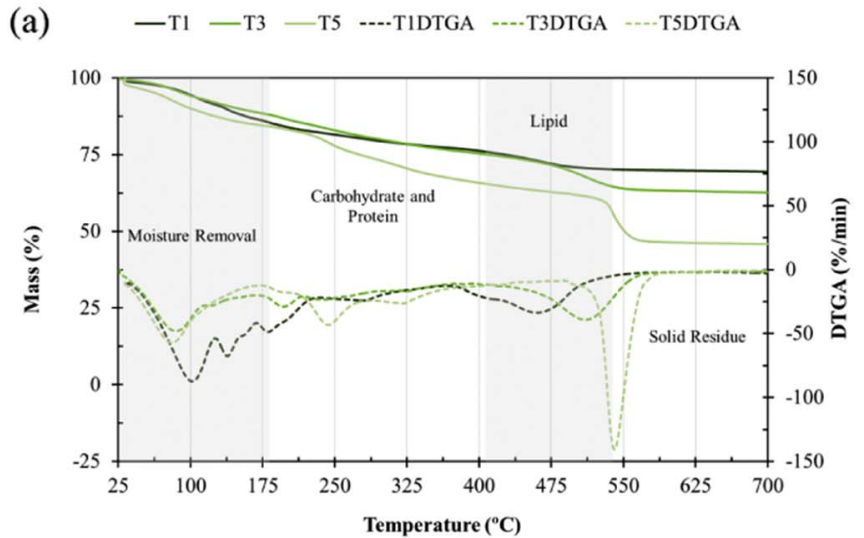

(b)

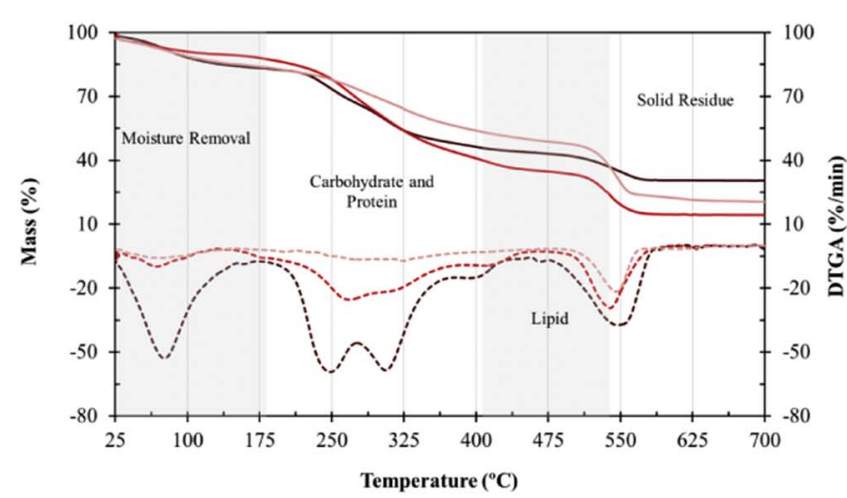

(c)

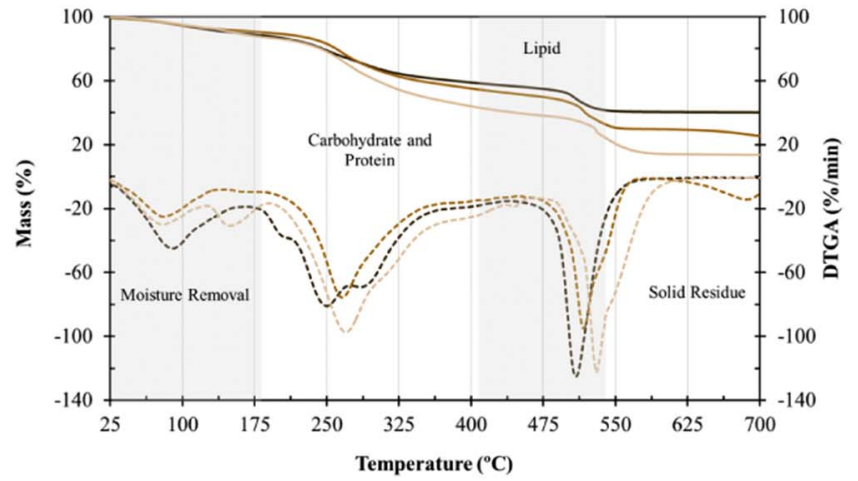

Fig. 2. Thermogravimetric analysis (TGA) and derivative TGA (DTGA) curves of the Nannochloropsis gaditana, Rhodomonas marina and Isochrysis sp. in treatments T1, T3 and T5. The different zones were based on Agrawal and Chakraborty [1] and Marcilla et al. [26].

components thermal resistance upon heating $[1,4]$. Fig. 2 shows the TGA and the DTGA curves for the three microalgae submitted to treatments $\mathrm{T} 1, \mathrm{~T} 3$ and $\mathrm{T} 5$. These were selected in order to verify the trend of the changes occurred in the microalgae thermal properties. Changes in the relative abundance and a displacement of the peaks in DTGA are noticeable for each one of the microalgae studied. The DTGA of microalgae evidenced that the composition of microalgae changed with the treatments applied.

In the dehydration stage $\left(25-180^{\circ} \mathrm{C}\right) \mathrm{N}$. gaditana and Isochrysis sp. presented different patterns in response to nutrients inputs. According to Marcilla et al. [26], these differences might be due to the location and strength of the intermolecular bonds between water molecules and the carbonaceous matrix, that influence the water elimination and so 
the peak temperatures and wideness. At this stage, processes such as the intrinsic breakdown of lipids and protein thermal unfolding may occur [4].

Former studies have examined the decomposition sequence of proteins, carbohydrates and lipids by TGA and demonstrated that the different intracellular components of microalgae are mainly decomposed as follows: firstly polysaccharides and proteins and finally lipids $[1,26]$. In the region commonly attributed to carbohydrate and protein content $\left(180-400{ }^{\circ} \mathrm{C}\right)$, it is possible to observe that for all the microalgae studied only the samples with the highest amounts of monosaccharides (T5 for $N$. gaditana and T1 for both $R$. marina and Isochrysis sp.) presented a maximum degradation peak around $250{ }^{\circ} \mathrm{C}$ in their DTGA. For instance, through Fig. $2 \mathrm{~b}$ it is possible to observe that the relative abundance of this peak in $R$. marina has a similar trend to that verified for TM and glucose (Table 2). Furthermore the absence of a maximum degradation step in the DTGA of $N$. gaditana might be explained by the low monosaccharide and protein contents observed for treatments with lowest nutrients inputs.

In the DTGA of Isochrysis sp. the peaks observed in the microalgae with the highest monosaccharide content (submitted to T1) seemed to have convoluted in the posterior treatments. These observations may indicate that, in the remaining samples (T3 and T5): $i$ ) the peak around $270{ }^{\circ} \mathrm{C}$ correspond to more than one substance and/or ii) the chemical composition of this microalga was altered by nutrients input.

In the TGA curves (Fig. 2), at the stage of solid residue decomposition $\left(>540^{\circ} \mathrm{C}\right)$, the microalgae from the lowest nutrients input treatments are those presenting the highest percentage of solid residue/ash content. This might suggest that microalgae under these limiting environmental conditions responded by decreasing the conversion rate of inorganic to organic compounds. The uptake and assimilation of nutrients by microalgae is tightly regulated by their bioavailability, concentrations and stoichiometry [17]. For instance, nitrogen assimilation is reported to be enhanced at nitrogen replete conditions [17]. Nitrogen is an essential component of catalysts and nucleotides (including ADP/ATP and NAD(P) + /NAD(P)H) which are crucial for keeping the reactions involving sugar interconversions and polysaccharide synthesis $[17,35]$. The stoichiometric imbalance between $\mathrm{Ci}$ and the other nutrients generated by keeping $\mathrm{Ci}$ constant may also have influenced the ash content. Moreover, the variation in microalgae thermograms between and within microalgae reflects the changes that occurred in their complex mixture of biomolecules.

\subsection{Principal component analysis (PCA)}

PCA was performed on the monosaccharides detected and on the maximum peaks temperature and amplitude in the regions commonly attributed to carbohydrates, proteins and lipids in DTGA. This multivariate analysis was performed to assess the relationship among monosaccharides and glycolipids and to verify if the maximum peaks of DTGA can be associated with sugars trends.

From the correlations matrix it was possible to observe some correlations between the variables studied. In $N$. gaditana a negative correlation between the solid residue, monosaccharides detected and total fatty acid (TFA), reported previously in Fernandes et al. [15], is observed suggesting that high mineral content, associated with low nutrients inputs, resulted in an overall low metabolites array. In $R$. marina, the amplitude of the maximum peak in the region $180-400{ }^{\circ} \mathrm{C}$ of DTGA (Amax1), glucose and TM are positively correlated, indicating that this peak is strongly influenced by glucose-based compounds that present low thermal stability (depicted by a strong negative correlation with Tmax1). With respect to Isochrysis sp., positive correlations between glycolipid, mannose, galactose and TFA, as well as with TM, glucose and solid residue were observed. The correlation observed for the first set of variables, corroborates the assumption previously made that mannose and galactose trends might reflect structural changes in Isochrysis cells.
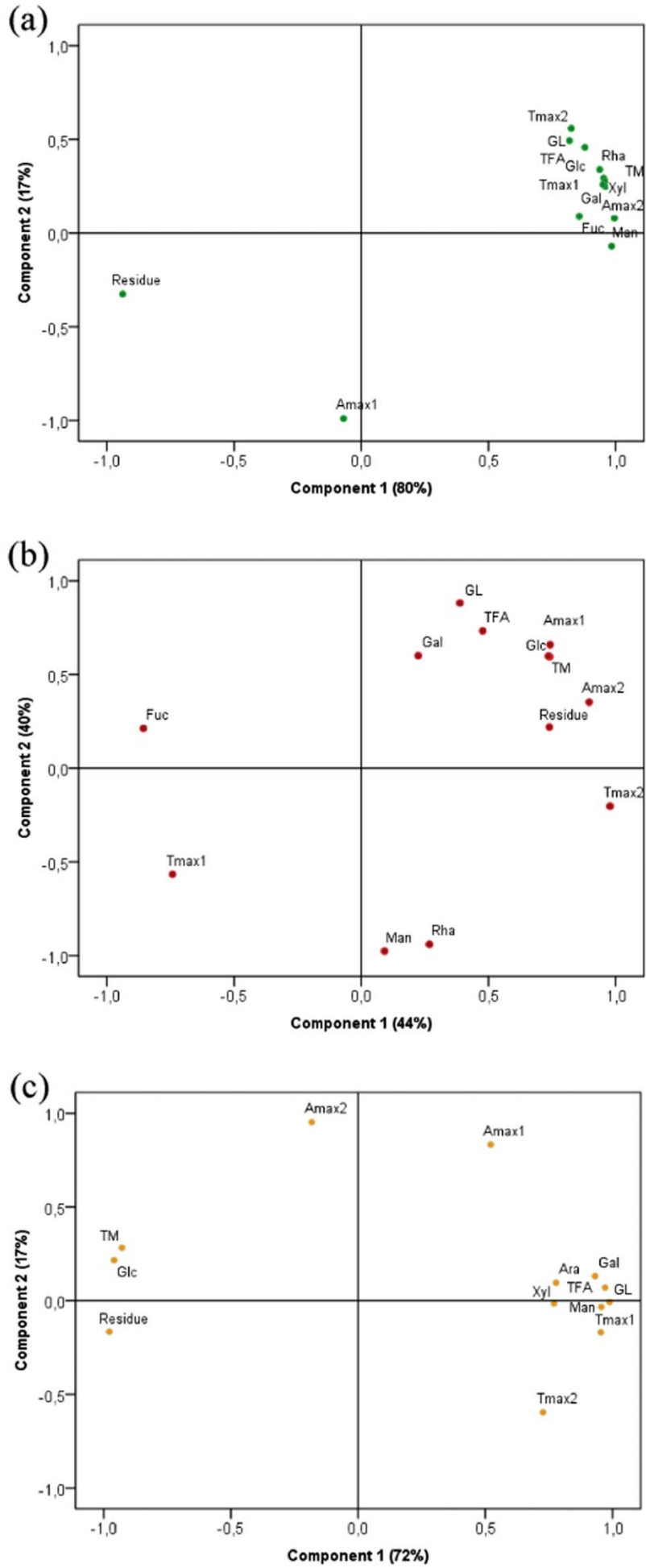

Fig. 3. Projection (Varimax rotation) of the loadings of components 1 and 2 in the PCA analysis based on the trends of the monosaccharides detected and maximum degradation peaks of a) Nannochloropsis gaditana, b) Rhodomonas marina and c) Isochrysis sp. Glc glucose; Gal - galactose; Man - mannose; Fuc - fucose; Xyl - xylose; Rha - rhamnose; Ara - arabinose; GL - glycolipids; TFA - total fatty acid; Tmax1 - maximum temperature in $180-400{ }^{\circ} \mathrm{C}$ region of DTGA; Tmax 2 - maximum temperature in $>400{ }^{\circ} \mathrm{C}$ region of DTGA; Amax 1 - amplitude of the maximum temperature in $180-400{ }^{\circ} \mathrm{C}$ region of DTGA; Amax2 - amplitude of the maximum temperature in $>400{ }^{\circ} \mathrm{C}$ region of DTGA.

Fig. 3 shows the distribution of the variables studied on the space defined by components 1 and 2 for the three marine microalgae subjected to treatments comprising low and high nutrients inputs. Through Fig. 3a that displays the variables for $N$. gaditana, we observed 
that the monosaccharides detected, the TFA and the glycolipid content as well as three of the four thermal parameters (Tmax1, Tmax2 and Amax2) plotted are constrained to one group which is positively correlated to component 1 in contrast to the solid residue. For $R$. marina, Fig. 3b shows that the variables are widely distributed in the factorial plan. In Isochrysis sp., Fig. 3c visualizes at least two main sets of variables, where glucose, TM and solid residue are negatively correlated to component 1 whereas the other monosaccharides detected as well as the TFA and glycolipid content are positively related to this component.

In a previous study, a highly branched $(1 \rightarrow 3,1 \rightarrow 6)-\beta$-D-glucan extracted from Isochrysis galbana was demonstrated to inhibit the proliferation of tumor cells [33]. Thus, the highest content of glucans previously mentioned for Isochrysis sp. might comprise highest content of this bioactive compound. Also, according to phylogenetic information $N$. gaditana store carbon in polysaccharides of this class of compounds ( $\beta$-D-glucan) and might present the health benefits mentioned above.

According to Brown et al. [7] the efficiency with which marine animals digests polysaccharide is dependent on the sugar composition and how the sugars are linked to each other. Thus glucose-rich polysaccharides are thought to be effectively digested by the digestive organs of molluscs and crustaceans whereas high concentrations of mannose may result in low digestibility of microalgae for these animals [7]. Thus, the minor mannose content and/or absence in Isochrysis sp. and $R$. marina with low nutrients concentrations may be a favorable aspect for the digestibility of microalgae.

\section{Conclusion}

The monosaccharide pattern of microalgae changed as nutrients availabilities increased and highlighted their taxonomic differences. Through comparison of the trend of glycolipid it was possible to indicate which monosaccharides had a structural role in microalgal cells. The thermal analysis seemed to indicate that the nutrients availability had an impact on the inorganic substrates assimilation. Furthermore, the depicted accumulation of glucose-based carbohydrates observed in Isochrysis sp. and $R$. marina in low nutrients availabilities is advantageous for carbohydrates applications.

\section{Acknowledgments}

This study was partially supported by the Oceanic Observatory of Madeira (M1420-01-0145-FEDER-000001-Observatório Oceânico da Madeira-OOM).

\section{Appendix A. Supplementary data}

The thermograms of treatments $\mathrm{T} 2$ and $\mathrm{T} 4$ can be seen in the figure of supplementary data. Supplementary data associated with this article can be found in the online version, at http://dx.doi.org/10.1016/j. algal.2017.04.023.

\section{References}

[1] A. Agrawal, S. Chakraborty, A kinetic study of pyrolysis and combustion of microalgae Chlorella vulgaris using thermo-gravimetric analysis, Bioresour. Technol. 128 (2013) 72-80.

[2] A.A. Arnold, B. Genard, F. Zito, R. Tremblay, D.E. Warschawski, I. Marcotte, Identification of lipid and saccharide constituents of whole microalgal cells by (1) (3)C solid-state NMR, Biochim. Biophys. Acta 1848 (2015) 369-377.

[3] M. Bar-Peled, M.A. O'Neill, Plant nucleotide sugar formation, interconversion, and salvage by sugar recycling, Annu. Rev. Plant Biol. 62 (2011) 127-155.

[4] A.P. Batista, L. Gouveia, N.M. Bandarra, J.M. Franco, A. Raymundo, Comparison of microalgal biomass profiles as novel functional ingredient for food products, Algal Res. 2 (2013) 164-173.

[5] A.B. Blakeney, P.J. Harris, R.J. Henry, B.A. Stone, A simple and rapid preparation of alditol acetates for monosaccharide analysis, Carbohydr. Res. 113 (1983) 291-299.

[6] M.R. Brown, The amino-acid and sugar composition of 16 species of microalgae used in mariculture, J. Exp. Mar. Biol. Ecol. 145 (1991) 79-99.

[7] M.R. Brown, S.W. Jeffrey, J.K. Volkman, G.A. Dunstan, Nutritional properties of microalgae for mariculture, Aquaculture 151 (1997) 315-331.

[8] C.-Y. Chen, X.-Q. Zhao, H.-W. Yen, S.-H. Ho, C.-L. Cheng, D.-J. Lee, F.-W. Bai, J.S. Chang, Microalgae-based carbohydrates for biofuel production, Biochem. Eng. J. 78 (2013) 1-10.

[9] L.M. Chevanton, M. Garnier, G. Bougaran, N. Schreiber, E. Lukomska, J.B. Bérard, E. Fouilland, O. Bernard, J.P. Cadoret, Screening and selection of growth-promoting bacteria for Dunaliella cultures, Algal Res. 2 (2013) 212-222.

[10] F.J. Choix, L.E. de-Bashan, Y. Bashan, Enhanced accumulation of starch and total carbohydrates in alginate-immobilized Chlorella spp. induced by Azospirillum brasilense: I. Autotrophic conditions, Enzym. Microb. Technol. 51 (2012) 294-299.

[11] D.T. Dennis, D.H. Turpin, D.D. Lefebvre, D.B. Layzell, Cytosolic carbon metabolism, in: D.T. Dennis, D.H. Turpin, D.D. Lefebvre, D.B. Layzell (Eds.), Plant Metabolism, Addison Wesley Longman Limited, Boston, 1997, pp. 81-160.

[12] P. Dörmann, C. Benning, The role of UDP-glucose epimerase in carbohydrate metabolism of Arabidopsis, Plant J. 13 (1998) 641-652.

[13] G. Dragone, B.D. Fernandes, A.P. Abreu, A.A. Vicente, J.A. Teixeira, Nutrient limitation as a strategy for increasing starch accumulation in microalgae, Appl. Energy 88 (2011) 3331-3335.

[14] S. Ermakova, R. Menshova, O. Vishchuk, S.-M. Kim, B.-H. Um, V. Isakov, T. Zvyagintseva, Water-soluble polysaccharides from the brown alga Eisenia bicyclis: structural characteristics and antitumor activity, Algal Res. 2 (2013) 51-58.

[15] T. Fernandes, I. Fernandes, C.A.P. Andrade, N. Cordeiro, Changes in fatty acid biosynthesis in marine microalgae as a response to medium nutrient availability, Algal Res. 18 (2016) 314-320.

[16] T. Fernandes, I. Fernandes, C.A.P. Andrade, N. Cordeiro, Marine microalgae growth and carbon partitioning as a function of nutrient availability, Bioresour. Technol. 214 (2016) 541-547.

[17] M. Giordano, J.A. Raven, Nitrogen and sulfur assimilation in plants and algae, Aquat. Bot. 118 (2014) 45-61.

[18] A.G. Giménez, Solvent extraction for microalgae lipids, in: E.M. Grima, M.J.I. González, M.A. Borowitzka, N.R. Moheimani (Eds.), Algae for biofuels and energy, Springer, Berlin, 2013, pp. 187-205.

[19] B. Gugi, T. Le Costaouec, C. Burel, P. Lerouge, W. Helbert, M. Bardor, Diatomspecific oligosaccharide and polysaccharide structures help to unravel biosynthetic capabilities in diatoms, Mar. Drugs 13 (2015) 5993-6018.

[20] M. Hildebrand, R.M. Abbriano, J.E. Polle, J.C. Traller, E.M. Trentacoste, S.R. Smith, A.K. Davis, Metabolic and cellular organization in evolutionarily diverse microalgae as related to biofuels production, Curr. Opin. Chem. Biol. 17 (2013) 506-514.

[21] A. Izumo, S. Fujiwara, Y. Oyama, A. Satoh, N. Fujita, Y. Nakamura, M. Tsuzuki, Physicochemical properties of starch in Chlorella change depending on the $\mathrm{CO}_{2}$ concentration during growth: comparison of structure and properties of pyrenoid and stroma starch, Plant Sci. 172 (2007) 1138-1147.

[22] J. Jia, D. Han, H.G. Gerken, Y. Li, M. Sommerfeld, Q. Hu, J. Xu, Molecular mechanisms for photosynthetic carbon partitioning into storage neutral lipids in Nannochloropsis oceanica under nitrogen-depletion conditions, Algal Res. 7 (2015) $66-77$.

[23] N.O.G. Jørgensen, Carbohydrates, in: G.E. Likens (Ed.), Encyclopedia of Inland Waters, Academic Press, Cambridge/Massachusetts, 2009, pp. 727-742.

[24] A. Karemore, R. Pal, R. Sen, Strategic enhancement of algal biomass and lipid in Chlorococcum infusionum as bioenergy feedstock, Algal Res. 2 (2013) 113-121.

[25] M. Koller, A. Muhr, G. Braunegg, Microalgae as versatile cellular factories for valued products, Algal Res. 6 (2014) 52-63.

[26] A. Marcilla, A. Gómez-Siurana, C. Gomis, E. Chápuli, M.C. Catalá, F.J. Valdés, Characterization of microalgal species through TGA/FTIR analysis: application to Nannochloropsis sp, Thermochim. Acta 484 (2009) 41-47.

[27] G. Markou, I. Angelidaki, D. Georgakakis, Microalgal carbohydrates: an overview of the factors influencing carbohydrates production, and of main bioconversion technologies for production of biofuels, Appl. Microbiol. Biotechnol. 96 (2012) $631-645$.

[28] J. Masojídek, G. Torzillo, M. Koblízek, Photosynthesis in microalgae, in: A. Richmond, O. Hu (Eds.), Handbook of Microalgal Culture: Applied Phycology and Biotechnology, John Wiley \& Sons, Chichester/West Sussex, 2013, pp. 21-36.

[29] Y. Mizuno, A. Sato, K. Watanabe, A. Hirata, T. Takeshita, S. Ota, N. Sato, V. Zachleder, M. Tsuzuki, S. Kawano, Sequential accumulation of starch and lipid induced by sulfur deficiency in Chlorella and Parachlorella species, Bioresour. Technol. 129 (2013) 150-155.

[30] S.M. Myklestad, E. Granum, Biology of $(1,3)-\beta$-glucans and related glucans in protozoans and chromistans, in: A. Bacic, G.B. Fincher, B.A. Stone (Eds.), Chemistry, biochemistry, and biology of (1-3)- $\beta$-glucans and related polysaccharides, Elsevier, Amsterdam, 2009, pp. 353-385.

[31] D.L. Nelson, M.M. Cox, Glycolysis, gluconeogenesis, and the pentose phosphate pathway, in: M.M. Nelson, W.H. Cox (Eds.), Lehninger: Principles of Biochemistry, Freeman and Company, Boston/New York, 2013, pp. 543-585.

[32] M.F.J. Raposo, R.M.S.C. Morais, A.M.M.B. Morais, Bioactivity and applications of sulphated polysaccharides from marine microalgae, Mar. Drugs 11 (2013) 233-252.

[33] I. Sadovskaya, A. Souissi, S. Souissi, T. Grard, P. Lencel, C.M. Greene, S. Duin, P.S. Dmitrenok, A.O. Chizhov, A.S. Shashkov, A.I. Usov, Chemical structure and biological activity of a highly branched $(1 \rightarrow 3,1 \rightarrow 6)$ - $\beta$-D-glucan from Isochrysis galbana, Carbohydr. Polym. 111 (2014) 139-148.

[34] M.J. Scholz, T.L. Weiss, R.E. Jinkerson, J. Jing, R. Roth, U. Goodenough, M.C. Posewitz, H.G. Gerkene, Ultrastructure and composition of the Nannochloropsis gaditana cell wall, Eukaryot. Cell 13 (2014) 1450-1464.

[35] G.J. Seifert, Nucleotide sugar interconversions and cell wall biosynthesis: how to bring the inside to the outside, Curr. Opin. Plant Biol. 7 (2004) 277-284. 
[36] A.F. Silva, S.O. Lourenço, R.M. Chaloub, Effects of nitrogen starvation on the photosynthetic physiology of a tropical marine microalga Rhodomonas sp. (Cryptophyceae), Aquat. Bot. 91 (2009) 291-297.

[37] M.J. Stadnik, M.B. de Freitas, Algal polysaccharides as source of plant resistance inducers, Trop. Plant Pathol. 39 (2014) 111-118.

[38] D.B. Stengel, S. Connan, Z.A. Popper, Algal chemodiversity and bioactivity: sources of natural variability and implications for commercial application, Biotechnol. Adv. 29 (2011) 483-501.
[39] D.W. Templeton, M. Quinn, S. Van Wychen, D. Hyman, L.M. Laurens, Separation and quantification of microalgal carbohydrates, J. Chromatogr. A 1270 (2012) $225-234$.

[40] F.L.-D. Cruz, E. Valenzuela-Espinoza, R. Millán-Núñez, C.C. Trees, E. Santamaríadel-Ángel, F. Núñez-Cebrero, Nutrient uptake, chlorophyll a and carbon fixation by Rhodomonas sp. (Cryptophyceae) cultured at different irradiance and nutrient concentrations, Aquacult. Eng. 35 (2006) 51-60. 